\title{
Artesão ou guasqueiro: Uma discussão sobre identidade e Memória
}

\author{
Artesano ou guasquero: Uma discucion sobre identidade e memoria
}

\author{
Craftsman or guasquero: A discussion about identity and memory
}

\author{
Juliana Porto Machado ${ }^{1}$ \\ Dr. Ronaldo Bernardino Colvero ${ }^{2}$
}

\begin{abstract}
Resumo
O artesanato em couro, guasquería, é uma prática tradicional que se mantém na contemporaneidade através das transformações de significados dos objetos produzidos e pela adoção de novos materiais de produção. As técnicas de produção são manuais, o que a caracteriza como artesanato. Possui forte ligação com a zona rural, principalmente com as atividades equestres. Nosso objetivo foi promover a análise desse processo artesanal tradicional do artefato em couro (guasquería) na cidade de Jaguarão e sua influência na identidade de seus praticantes, levando em conta o saber/fazer do artesão/guasqueiro para compreender se houve modificações e como ocorre a conservação-transformação das técnicas de produção. A metodologia consistiu em uma proposta etnográfica através de entrevista semiestruturada com 04 artesãos/guasqueiro. Como principais resultados podemos destacar: a partir das narrativas de nossos informantes que todos os entrevistados viveram ou trabalharam na zona rural; persistem as técnicas tradicionais/contemporâneas e o modo de produção; continua o saber/fazer apreendido pela transmissão de conhecimento entre indivíduos que possuíam laços íntimos com o aprendiz; o meio urbano/rural em que a prática de guasquería é um artesanato "rural", onde seus criadores vivem em espaço urbano; por fim, a visão do guasqueiro, em relação ao sua identidade, é de se considerar guasqueiro por trabalhar com couro cru e artesão por trabalhar de forma manual. Concluímos que os praticantes desse oficio se consideram guasqueiros, mas também, artesão. Em um diálogo não conflituoso. O eu guasqueiro e o eu artesão se complementam.
\end{abstract}

Palavras-chave: Guasqueria, Identidad, Memória, Cuero-crudo, Artesania.

\section{Resumén}

La artesanía em cuero, guasquería, es una práctica tradicional que queda em la contemporaneidad a través de llas transformaciones de los significados de los objetos producidos y por la adopción de nuevos materiales de producción. Las técnicas de producción son manuales, lo que caracteriza como artesanía. Tiene um fuerte vínculo con el campo, especialmente con actividades ecuestres. Nuestro objetivo era estudiar la artesanía tradicional y los procesos de artefacto en cuero (guasquería) en la ciudad de Jaguarão e su influencia em la

\footnotetext{
${ }^{1}$ Mestranda no Programa de Pós-graduação em Memória Social e Patrimônio Cultural pela UFpel. Bacharela em Produção e Política Cultural pela Unipampa-Jaguarão.

${ }^{2}$ Diretor do campus de São Borja - UNIPAMPA, Mestre em História Regional - UPF - Passo Fundo - RS, Doutor em História das Sociedades Ibéricas e Americanas - PUC - Porto Alegre, Prof. Adjunto da Universidade Federal do Pampa - UNIPAMPA - Campus de São Borja e Professor do Mestrado em Políticas Públicas da UNIPAMPA campus São Borja e do Programa de Pós-Graduação em Memória Social e Patrimônio Cultural UFPEL
} 

e-ISSN 2016/Atual: 2525-7870 | e-ISSN 2015/2016: 2447-018X

identidade de sus practicantes, tomando em cuenta el saber/hacer/ del guasqueiro/artesano entender si ha habido cambios y la conservación-transformación de las técnicas de producción. La metodologia consistió en una propuesta etnográfica a través de la entrevista semiestructurada con 04 guasqueiro/artesanos. Se observó que todos los entrevistados han vivido o trabajado en el campo y que los artefactos tradicional/contemporâneo persisten las técnicas y el modo de producción - el saber/hacer - entre individuo aprendiz y el maestro tradicional; por último, la visión de los informantes, en relación con su trabajo, es que para se considerar un guasqueiro es necesario trabajar con cuero crudo y dominarlo para trabajar manualmente. Concluimos que el guasqueiro sigue produciendo sus obras com las mismas técnicas de producción, mantiene rasgos tradicionales, modifica estilos pero guardan el saber/hacer, incluso en el contexto Mercantil.

Palavras-claves: Guasqueria, Identidad, Memória, Cuero-crudo, Artesania.

\begin{abstract}
The leather handicraft, guasquería, is a traditional practice that remains in the contemporaneity through the transformations of meanings of the produced objects and the adoption of new materials of production. The techniques of production are manual, which characterizes it as crafts. It has strong connection with the rural area, mainly with equestrian activities. Our objective was to promote the analysis of this traditional artisan process of the leather artifact (guasquería) in the city of Jaguarão and its influence on the identity of its practitioners, taking into account the know-how of the craftsman / artisan to understand if there were modifications and how Conservation and transformation of production techniques. The methodology consisted of an ethnographic proposal through a semi-structured interview with 04 artisans / guasqueiro. As main results we can highlight: from the narratives of our informants that all the interviewees lived or worked in the rural area; Traditional / contemporary techniques and the mode of production persist; Continues to know / make understood by the transmission of knowledge between individuals who had intimate ties with the learner; The urban / rural environment in which the practice of guasquería is a "rural" handicraft, where its creators live in urban space; Finally, the view of the man in relation to his identity is to consider himself as a guasqueiro for working with rawhide and craftsman for working in a manual way. We conclude that the practitioners of this trade consider themselves as guasqueiros, but also, artisan. In a nonconflict dialogue. The Iguaçu I and the artisan self complement each other.
\end{abstract}

Keywords: Guasqueria, Identity, Memory, Leather-Raw, Craft.

\title{
1.Introdução
}

A guasquería é um ofício que trabalha com couro cru animal para a produção de peças voltadas para a atividades do campo, como a equestre ${ }^{3}$ e também indumentárias da pilcha gaúcha ${ }^{4}$.

Surge em meados do século XVI, na américa latina, com a introdução do gado bovino. Esses animais são incorporados nas terras pampianas, através dos colonizadores portugueses e espanhóis, voltados para suprir a alimentação das recentes comunidades formadas.

No período em que os jesuítas fixam suas reduções esse gado começa a ser criado em confinamento. Com o fim das comunidades jesuíticas, os animais foram abandonados, ficaram soltos nos campos e se reproduziram livremente. Com a grande quantidade desses, não apenas a carne mais também o couro passa a ser produto de exploração. Essa matéria-

\footnotetext{
${ }^{3}$ Equipamento de encilhar o animal como rédeas, freios, basto, rebenque, estribos, barrigueira, bolhadeiras e outros.

${ }^{4}$ Como arrastas, tipo de cinto que vai sobre a bombacha.
} 
prima era utilizada pelos índios para a confecção de vestes, de utensílios e de instrumentos de caça (LUVIZOTTO, 2010).

A fixação das grandes fazendas nas regiões sulistas, fez com que o homem campeiro, o gaúcho ${ }^{5}$, começa-se a utilizar o couro cru para produzir seus aparatos de trabalho. No princípio as técnicas eram rudimentares voltadas apenas para uma utilidade cotidiana.

Com o passar do tempo, as técnicas outrora simples de apenas couro liso. Passam por um processo de retradicionalização, novos elementos são incorporados e esse saber/fazer se aprimora ao longo de sua produção. Sendo considerado um ofício artesanal (GARCIA, 2009).

Para tanto, considerada uma prática artesanal, a guasquería, está em um processo de valorização em meio a mobilização da diversidade cultural, das memórias coletivas/individuais e identidades locais, frente a sociedade homogeneizadora. $\mathrm{O}$ artesanato apresenta obras únicas e criativas, que são suportes simbólicos.

É necessário conhecer todo o processo envolvido na produção, consumo e circulação de peças artesanais para compreender a complexidade envolvida nesse ofício que envolve a tríade tradição-modernidade-identidade. $\mathrm{O}$ artesanato como um saber/fazer aprendido e transmitido influência na formação da identidade de seus praticantes. Uma tradição passada de mãe/pai para filho (a).

A tradição no sentido de transmissão de um conhecimento, sem tantas alterações ao longo do tempo. Nesse sentido, essa como hábitos, costumes e saberes passados de um sujeito a outro, que aceita modificações. Se readaptando ao meio e aos sujeitos (HOBSBAWM; RANGER, 1984).

O artesanato em couro cru, é uma prática cultural, cujo artesão é conhecido popularmente como guasqueiro, aquele que trabalha com guasca (tiras de couro). A atividade de guasquería em Jaguarão, município que se localiza no extremo sul do Rio Grande do Sul e que faz fronteira com a cidade de Rio Branco no Uruguai, pode ser considerada como complemento de renda familiar, profissão ou um estilo de vida.

O mercado para esses objetos artesanais, na maioria dos casos, é representado por estabelecimentos de correaria, de veterinárias e por encomendas. O consumo se apresenta pelos indivíduos sociais e culturais que possuem relações diretas ou indiretas com atividades ligadas a área rural, como a equestres.

\footnotetext{
${ }^{5}$ Homem do campo, livre, nômade e bandoleiro. No entanto com a fixação das grandes fazendas esse torna-se peão e também figura típica das regiões do Sul do pampa.
} 
A partir disso, o objetivo foi promover a análise desse processo artesanal tradicional do artefato em couro (guasquería) na cidade de Jaguarão e sua influência na identidade de seus praticantes.

A metodologia adotada para a realização do objetivo proposto foi pesquisa qualitativa de cunho etnográfico com 04 (quatro) guasqueiros/artesãos, a partir do método de entrevista semiestruturada, de observação participante. Utilizando veículos de coletas de informação como fotografia, filmagem, gravações de áudio e diário de campo.

Nesta perspectiva o pesquisador interpreta as ações do sujeito observado, conhece o sentido próprio das ações do outro pelo outro, como ele se percebe em meio aos significados que constrói em sua cultura (ERICKSON, 1986). Expondo o Ethos e o habitus dos sujeitos (GEERTZ, 2008), os valores constituídos, as cargas simbólicas, o capital humano e as relações do sistema social. Então a pesquisa etnográfica nas palavras de Geertz $(2008$, p. 7):

[...] é uma descrição densa. O que o etnógrafo enfrenta, de fato - a não ser quando (como deve fazer, naturalmente) está seguindo as rotinas mais automatizadas de coletar dados - é uma multiplicidade de estruturas conceptuais complexas, muitas delas sobrepostas ou amarradas umas às outras [...] do seu trabalho de campo, mesmo o mais rotineiro: entrevistar informantes, observar rituais, deduzir os termos de parentesco, traçar as linhas de propriedade, fazer o censo doméstico [...] escrever seu diário. Fazer a etnografia é como tentar ler (no sentido de "construir uma leitura de") um manuscrito estranho, desbotado, cheio de elipses, incoerências, emendas suspeitas e comentários tendenciosos, escrito não com os sinais convencionais do som, mas com exemplos transitórios de comportamento modelado (GEERTZ 2008, p. 7)

Sendo a etnografia uma abordagem qualitativa, para Walcott (1992) essa pode ser brevemente entendida a partir de três processos. Em que o primeiro é a ação de ver e ouvir, o pesquisador escreve as impressões obtidas pelo sujeito/objeto. Já o segundo é o momento em que o pesquisador questiona e troca ideias com o participante da pesquisa. E o terceiro e a organização do material adquirido. Esses processos são integrantes e fazem com que o pesquisador tenha um importante acervo de informações (WALCOTT, 1992).

A entrevista é um espaço de negociação, de troca de conhecimento entre entrevistador e entrevistado, em um jogo de interpretações (FONTANA; FREY, 2000). Nesta pesquisa o método será de entrevista semiestruturada, em que essa é norteada de forma mais espontânea, possibilitando ao entrevistado maior liberdade para responder as questões.).

As questões são dirigidas por tópicos relevantes a demanda de resolução do problema. Com o rol adquiridos durantes a entrevista é possível que o entrevistador consiga elaborar questões mais especificas e pertinentes. Sendo desnecessário a elaboração de um questionário fechado e limitado (MARCONI; PRESOTTO, 2011). 


\section{Discussão}

\subsection{Artesanato}

$\mathrm{O}$ artesanato inicialmente tinha a função de suprir uma demanda, as criações eram voltadas para serem utilizadas em atividades do cotidiano. De acordo com Covelo e Mateos (2010) o artesão era parte de um grupo, ou seja, não existia o caráter individual do artista, as obras eram criação de todos. Assim, muitos objetos encontrados por arqueólogos ao longo dos séculos não possuem identificação do autor.

Com o passar do tempo, o artesão torna-se o sujeito possuidor do conhecimento de um ofício manual e a capacidade de transmitir esse para seus aprendizes. Comercializava suas obras no espaço urbano, onde se estabeleceram os grandes ateliês. E nas comunidades rurais os pequenos ateliês predominavam, cumprindo com a função inicial de prover as necessidades diárias, como no trabalho do campo e no manejo de animais (COVELO; MATEOS, 2010).

Até meados do século XX o artesanato ainda era tido como uma fonte de resistência a supremacia da mecanização, mas como nada se mantém em seu estado original, o artesanato também acaba por se adaptar as mudanças que ocorrem em uma sociedade. Segundo Dupey (2006) um marco importante a ser mencionado foi em 1960, quando obras artesanais são expostas em museus.

No século XX, na América Latina, o artesanato realiza um movimento de deslocamento, no qual, antes era uma prática apenas das pequenas comunidades rurais, porém com o êxodo do campo para cidade, possibilita que esse ofício esteja presente nos grandes centros urbanos (DUPEY, 2006).

Com isso, o artesanato é definido pela Organização das Nações Unidas para a Educação, a Ciência e a Cultura (UNESCO) no Simpósio Internacional/CCI de 1997, como:

\footnotetext{
"Produtos artesanais são aqueles confeccionados por artesãos, seja totalmente à mão, com o uso de ferramentas ou até mesmo por meios mecânicos, desde que a contribuição direta manual do artesão permaneça como o componente mais substancial do produto acabado. Essas peças são produzidas sem restrição em termos de uantidade e com o uso de matérias primas de recursos sustentáveis. A natureza especial dos produtos artesanais deriva de suas características distintas, que podem ser utilitárias, estéticas, artísticas, criativas, de caráter cultural e simbólicas e significativas do ponto de vista social" (UNESCO, 1997, apud BORGES, 2011, p. 21).
}

Dessa forma, conceituar a prática artesanal é discorrer sobre os diversos âmbitos de formação de uma sociedade, levando em consideração as mudanças, o tempo, o espaço e o 
sujeito. Esta prática artesanal-cultural engendra todas as esferas socioculturais e é detentora de valor simbólico e de capital humano.

Para Keller (2010) o artesanato pode ser definido como algo heterogêneo, é uma expressão cultural que está entre a tradição e a modernidade. Seu grau de valorização se apresenta pela característica que possui de ser meio de inclusão sociocultural, uma vez que, é fonte de geração de renda, é uma profissão, um condutor de resgate dos valores culturais e locais.

Para Rotman (pg. 147, 2013) “o artesanato possui uma dimensão patrimonial; expressa características significativas para a compreensão da vida dos diferentes grupos humanos. Assim, compromete múltiplos aspectos de sua realidade histórica, econômica e sociocultural”.

Do mesmo modo, o trabalho artesanal possui a característica de ser uma atividade de produção manual exercido em sua grande parte por grupos sociais familiares de forma informal como uma complementação de renda e faz parte da sociedade contemporânea (KELLER, 2014).

\subsection{Identidade e Memória}

A memória coletiva está sempre em uma continuidade, o indivíduo lembra, retém do passado somente aquilo que permanece na consciência do grupo, suportes dessa no tempo e no espaço, possui duração ligada aos membros do grupo. De tal maneira, não existem meios de "guardar" todas as lembranças em suas matizes e formas, do contrário acessaríamos essas sempre que desejássemos, podemos evoca-las mais nitidamente com o apoio dos suportes da memória coletiva (HALBWACHS, 1990).

Para Bosi em Memória e Sociedade (2001) a memória hábito corresponde a uma resposta a demanda da sociedade e da cultura, em um processo de aprendizado que ocorre até ser fixado e transformado em algo cotidiano. Logo, Bergson (1999), a memória tem como função primordial guardar o passado, para que esse esteja vivo sendo evocado ao presente através das lembranças, já que o presente conduz a ação e o passado é estático, mas mantendo-se ativo no espirito, entendido como o inconsciente.

A lembrança é que nos permite percebe que o passado ainda existe e se conserva, pois em todo espírito o passado sobrevive e todo homem tem espirito. A consciência nos possibilita exteriorizar esse passado por meio das representações de imagens/lembranças, porém só se mantém puro no espirito, onde todas nossas recordações psíquicas estão seguras e preservadas (BERGSON, 1999). 

e-ISSN 2016/Atual: 2525-7870 | e-ISSN 2015/2016: 2447-018X

A metamemoria, é elemento primordial para a construção identitária é individual ou coletiva, e a forma como o sujeito interpreta as lembranças recordadas e as reivindica. $\mathrm{O}$ conhecimento e reconhecimento que se tem dessas, a representação que faz de sua própria memória em relação de troca com o seu passado, o discurso e postura que cada sujeito tem de suas memorias pessoais (CANDAU, 2011).

No caso, ao comunicarmos nossas memórias para outros estamos utilizando a metamemoria, a ideia de patrimônio é um exemplo dessa forma memorial. Assim, a metamemoria transmite uma narrativa de crenças comuns para as memorias individuais, ou seja, a única memória que pode ser compartilhada. Então, de acordo com Candau (2011) metamemoria é a única possibilidade de uma memória coletiva.

Deste modo, a memória pode ser entendida como uma reinterpretação e modificação continua e atualizada do passado, vai além de uma retransmissão do passado completo e intacto. E a possibilidade de uma memória coletiva só poderá acontecer através da metamemoria, em um discurso de que membros de um grupo irão produzir a cerca de uma memória supostamente comum e reconhecida por todos.

Dessa forma, Candau (2011), trata das metáforas de memórias compartilhadas, quem não possuem teor empírico, considerando apenas alguns elementos socioculturais. Porém, não há como nos desprendermos dos efeitos das generalizações, já que esses transmitem de certa forma fatos da realidade, para tanto, o que se entende por memória coletiva pode ser interpretado por meio das retoricas holistas.

A partir de certas generalizações, de termos, de códigos, de imagens, de gestos, de hábitos que construiriam uma ilusão de estabilidade homogênea de lembranças compartilhadas.

\footnotetext{
"Um reagrupamento de indivíduos (a comunidade, a sociedade, o povo) [...] representações, crenças, recordações (ideologia $\mathrm{X}$ ou $\mathrm{Y}$, a religião popular, a consciência ou a memória coletiva) ou ainda elementos imaginários (identidade étnica, identidade cultural) (CANDAU; p. 29, 2011) ”.
}

Para Candau (2011), a identidade é criada socialmente a partir das interações, das trocas de saberes e das relações, que fazem com que se estabeleça um vínculo, uma sensação de reconhecimento e de afinidade com certos contextos, objetos, símbolos e sujeitos. A identidade, por sua vez, possui uma relação de dependência com a memória, uma beneficia a outra mutuamente produzindo uma história. 
A memória tem como tarefa relembrar o passado, mas pode ser remodelada pelos indivíduos, o esquecimento é a válvula de escape, o local de descarte das lembranças quando essas se tornam penosas ou causam a separação dos grupos sociais. De acordo com Hall (2005, p.46) “[...] o sujeito do iluminismo, visto como tendo uma identidade fixa e estável, foi descentrado, resultando nas identidades abertas, contraditórias, inacabadas, fragmentadas, do sujeito pós-moderno".

\subsection{Tradição e Modernidade}

A tradição é uma construção humana, surge de uma necessidade. Para, Lenclud (2013) possui a característica de ser passível de ser retransmitida e reinterpretada. De modo que, não tem como se manter original. Em meio a uma sociedade a cultura nunca se estagna, novas ações nascem, novos valores vão ser criados em oposição aos valores tradicionais existentes, que iram perde seu espaço (LENCLUD, 2013).

Para que os saberes tradicionais sobrevivam ao ciclo natural de criação/transformação, são necessárias as concessões. Esses devem se adaptar as alterações impostas pelo contexto em que estão inseridos. Caso contrário irão desaparecer e novas tradições serão criadas (LENCLUD, 2013).

Como ressalta Hobsbawm e Ranger (1984) localizar uma tradição dita autentica é uma tarefa impossível. Pois, não existem meios ou registros para se saber quando começaram. Então toda tradição é uma invenção, se manifesta por meio de ritos e costumes ligados a certos elementos do passado. Contudo, só é criada quando práticas antigas se dissolvem e se perdem (HOBSBAWM; RANGER,1984).

Assim, na emergência do século XVIII, na Europa, os costumes ainda permaneciam, estavam presentes nesse contexto de forma arreigada, definindo-se como costume a ação que praticam um grande número de indivíduos. Com a emergência de um novo tempo que supostamente transformaria a cultura do povo, assim, não haveria a necessidade da existência de costumes antigos/primitivos/bárbaros, que não teriam mais espaço de representatividade (THOMPSON, 1998).

Segundo Jameson (2004), a modernidade é o período no qual a inovação tecnológica passou a ser indispensável à vida em sociedade. Então, modernidade e tecnologia formam um todo, são interdependentes, são sinônimas, onde, os países passaram a buscar os mecanismos técnicos como geradores de mudanças sociais, culturais, políticas e econômicas. 
A modernidade como a forma de viver em sociedade, com a adoção de novos costumes e estilos frente às transformações sociais. Para Giddens (1991) as mudanças fazem com que o homem deposite sua confiança mais no dinheiro (fichas simbólicas), nos sistemas peritos e abstratos do que nas pessoas envolvidas em suas relações sociais. Logo, todas essas modificações na sociedade afetam as memórias e identidades dos sujeitos.

Dessa forma, a tradição como mecanismo de transmissão possibilita que alguns elementos que sejam fortemente organizados em estruturas socioculturais sólidas possam ser memorizados e assim compartilhados. A relação lembrar/esquecer é o que possibilita as ações das tradições e até mesmo sua existência (CANDAU, 2011).

Assim, de acordo com Candau (2011), a forma que a sociedade encontra para enfrentar o temor das mudanças, das perdas e principalmente o esquecimento é conservar suas tradições, memórias artificiais, identidades e saberes como uma forma salvaguarda-lo para não ser perdido no distanciamento tempo-espaço.

\subsection{Guasqueiro e/ou artesão}

A guasquería é uma técnica artesanal em couro que apresenta em sua estrutura de produção nomenclaturas próprias para designar a criação de suas obras. Para isso serão exemplificados alguns desses termos, que são essenciais para a compreensão do que vem a ser o trabalho do guasqueiro.

Em um primeiro momento ocorre a obtenção e a escolha da matéria-prima, que no caso é o couro de animais, normalmente da espécie bovina. Pode se conseguir esse material por meio da compra em frigoríficos ou de forma tradicional com a carneada, onde ocorre o abate do animal e consequentemente a retirada de seu couro.

Em seguida esse couro será limpo (com água e sabão natural) e será estaqueado, esse processo consiste em colocar o couro em um suporte de madeira (estacas) para secar ao sol. Depois de seco esse é extraído das estacas e será lonqueado, os pêlos que cobrem o couro serão raspados com o auxílio de uma faca ou navalha, com toda atenção para não causar danos ao material.

Na sequência esse couro irá ser cortado em loncas e depois sovado com o sovador, que é um pedaço de madeira usado para amaciar o couro. Logo, o guasqueiro dará início a tirar tentos, que são tiras finas em couro utilizadas para trançar e criar peças que compõem os arreios de montaria como cabeçalhos para freios, rebenques, botões, corredores e outros.

Neste sentido, transformar o couro cru em peça artesanal perpassando por todo esse processo manual mencionado anteriormente, influência diretamente na identidade desse 
guasqueiro e/ou artesão. Utilizaremos neste artigo iniciais para identificarmos os entrevistados.

O entrevistado M.T se identificou em um primeiro momento como artesão, devido ao fato de possuir uma carteirinha disponibilizada pela prefeitura da cidade, que o identificava como tal. Sua dúvida em relação a como se denominar era visível. Para tanto, esclareceu "antes era guasqueiro", mas agora, "eles não dizem guasqueiro quando se vai fazer a carteira, aí não sei dizer pode ser guasqueiro, pode ser acho que guasqueiro e artesão" (M.T, 2015).

Para ele ser guasqueiro, em suas palavras, significa "trabalhar o couro cru, estaquear e lonquear para fazer as cordas". Então, o guasqueiro seria o sujeito que trabalha especificamente com couro cru e que realiza todo o processo de manejo do couro, até torna-lo apto para ser modificado artesanalmente.

Em relação ao fato de antes apenas ser guasqueiro, o entrevistado J.M. (2015) afirma, artesão, "inventaram isso agora". Ou seja, para ele o artesão é uma definição atual. Em sua concepção ser guasqueiro é como sua profissão, por mais que seja aposentado ele pratica esse ofício. Neste sentido, a igualdade entre artesão e guasqueiro está no fato de ambos trabalharem manualmente.

O ofício de guasquería se caracteriza como tal, de acordo com P.G quando a matéria prima principal é exclusivamente o couro cru. A utilização de couro branco, o couro tratado industrialmente, para ele é um material ruim para se trabalhar, devido a utilização de produtos químicos. Então, é guasqueiro quando perguntado, porque, a definição de artesão em suas palavras não lhe "agrada, porque vejo os que se consideram artesão e fazem uns trabalhos tão assim, então por que não posso ser também se eu faço esse trabalho tão difícil” (P.G, 2015).

Já J.S (2015) menciona o fato de produzir suas ferramentas desde furador a alicate, utiliza um chifre de touro para dar acabamento em suas peças. Prefere não usar ferramentas industrializadas. Seu saber fazer aprendido foi transmitido para seu filho. Em suas palavras explica que a técnica de tranças “está em extinção ninguém quer mais fazer” (J.S, 2015).

Para tanto, “guasquería é artesanato, não é como uma fábrica que sempre vai sair certo, é artesanato comum nem sempre vai sair perfeito" (J.S, 2015). Demonstrando em sua fala a diferença que o artesanato tem em relação ao produto industrializado. E é nessa imperfeição que o artesanato constrói seu espaço, através de desenhos criativos, diferentes, que os tornam singulares. (CANCLINI ,1983).

\section{Conclusões}


RELACult - Revista Latino-Americana de Estudos em Cultura e Sociedade

Concluímos que os praticantes desse ofício se consideram guasqueiros, mas também, artesão. Em um diálogo não conflituoso. O eu guasqueiro e o eu artesão se complementam.

A guasquería é um artesanato que trabalha com couro e ferramentas manuais, possui dimensões tradicionais como a repetição, a transmissão do saber de uma geração a outra, caráter observado principalmente nas técnicas de produção. Sua criação é feita em ateliês com aspecto simples, com estrutura de pequenos galpões de estâncias.

Esses espaços têm obras acabadas e inacabadas de guasca, sendo nesse contexto familiar que remete ao rural, ao campo que o guasqueiro dá início a fabricação de suas obras. De alguma forma o ateliê acaba sendo um lugar de lembranças, inspirações dos tempos que esses indivíduos trabalhavam como campeiros e residiam na zona rural e também de fuga da realidade urbana em que estão inseridos atualmente.

Essa dimensão que o artesanato possui de permear o campo social e o simbólico lhe permitindo ser um meio de criação em que o indivíduo pode usar de todo o seu saber/fazer, de suas técnicas de produção e estilismo. Logo, a guasquería é uma prática secular que possui uma história própria, tem um legado de transmissão de conhecimento popular de sujeitos profundamente ligados a um estilo de vida próprio.

Por mais que eles tenham abandonado o espaço físico rural eles ainda possuem a identidade de "eu campeiro", de "eu cavaleiro" e do "eu rural". Essas identidades compõem o "eu guasqueiro" que permeia dois contextos diversos e até mesmo opostos, urbano/rural. Por fim, a guasquería tem valor humano e simbólico, e por isso, é um elemento cultural.

\section{Referências}

BERGSON, Henri. Matéria e Memória. Ensaio sobre a relação do corpo com o espírito. SP: Martins Fontes, 1990.

BORGES, A. Design + Artesanato - O caminho brasileiro. São Paulo: Terceiro Nome, 2011.

BOSI, Ecléia. Memória e Sociedade: Lembrança de velhos. SP: Companhia das Letras, 1985.

CANCLINI, Néstor G. As Culturas Populares no Capitalismo. Trad. Cláudio N.P. Coelho. São Paulo: Brasiliense, 1983.

CANDAU, Joel. Memória e identidade. Tradução: Maria Leticia Ferreira. São Paulo: Contexto, 2011.

COVELO, Natalia; MATEOS, Cristina. Mercado De Artesanías En El Uruguay. Monografia. Faculdad de la Republica, 2010. 
RELACult - Revista Latino-Americana de Estudos em Cultura e Sociedade e-ISSN 2016/Atual: 2525-7870 | e-ISSN 2015/2016: 2447-018X

CHIZZOTTI, Antônio. Pesquisas em Ciências Humanas e Sociais. São Paulo: Cortez, 1991.

GARCÍA, Rocío. De la yerra a la Vitrina: Transformaciones contemporáneas de la guasquería. Montevideo: Trama Revista de Cultura y Patrimonio. ano 1, $\mathrm{n}^{\circ} 1$, setembro 2009.

DUPEY, Ana María. La Práctica Del Antropólogo En Un Proyecto De Desarrollo Artesanal Entre Teleras De Santiago Del Estero Y Cesteras Del Pueblo Pilagá. Revista del CIDAP: Artesanías de América, nº 62, 2006.

ERICKSON, F. Qualitative methods in research on teaching. In: WITTROCK, M. C. (Ed.). Handbook of research on teaching. 3. ed. New York: Macmillan Publishing Company, 1986, p.119-161.

FONTANA, A.; FREY, J.H. The interview, from structured questions to negotiated text. In: DENZIN, N. K.; LINCOLN, Y.S. Handbook of qualitative research. 2nd. Ed. Thousand Oaks: Sage Publications, 2000, p. 645-672.

GEERTZ, Clifford. A Interpretação das Culturas. Rio de Janeiro: LTC, 2008.

GIDDENS, Anthony. As consequências da modernidade. Tradução de Raul Fiker. São Paulo: UNESP, 1991.

HALBWACHS, Maurice. A Memória Coletiva. São Paulo: Ed. Centauro, 2004.

HALBWACHS, Maurice. Los marcos sociales de la memoria. Caracas: Anthropos Editorial, 2004.

HOBSBAWM, Eric \& RANGER, Terence. A Invenção das Tradições. Rio de Janeiro:Paz e Terra, 1984.JAMESON, Frederic. Una modernidad singular: Ensayo sobre la ontologia del presente. Barcelona; Gedisa; 2004.

KELLER, Paulo. O artesão e a economia do artesanato na Sociedade contemporânea. Maranhão: Revista de Ciências Sociais Política e Trabalho, 2014.

LACARRIEU, Mónica.El patrimonio cultural inmaterial: un recurso político en el espacio de la Cultura Pública Local. Santiago de Chile: DIBAM, 2004.

LENCLUD, Gérard. A Tradição não é mais o que era: Sobre as noções de Tradição e de Sociedade Tradicional em Etnologia. Brasília: História, histórias. vol. 1, n. 1, 2013.

MACDOUGALL, David. The visual in Anthropology. In. The corporeal image. Film, ethnography and the senses. Princeton, New Jersey, Princeton University Press, 2006.

MARCONI, Marina de Andrade; PRESOTTO, Zelia Maria Neves. Antropologia: Uma Introdução. São Paulo: Atlas, 2011. 
RELACult - Revista Latino-Americana de Estudos em Cultura e Sociedade

Revista Latinoamericana de Estudios en Cultura y Sociedad | Latin American Journal of Studies in Culture and Society

V. 03, ed. especial, ago., 2017, p. 129-141 | relacult.claec.org e-ISSN 2016/Atual: 2525-7870 | e-ISSN 2015/2016: 2447-018X

ROTMAN, Mónica. Las múltiples y Complejas Articulaciones entre los Campos del Patrimonio y de las Artesanías. In: Diversidade Cultural y Estado: Escenários y desafios de hoy. Argentina: Primer Encuentro Nacional de Patrimonio Vivo, 2015.

THOMPSON, E.P. Costumes em comum - Estudos sobre cultura popular tradicional. São Paulo: Companhia das letras, 1998.

TASSO, Alberto. Teleras y sogueros. La artesanía tradicional de Santiago del Estero entre la cultura, la historia y el mercado. Buenos Aires: V Congreso Nacional de Estudios del Trabajo, 2001.

UNESCO. Convención para la salvaguardia del patrimonio cultural inmaterial. $32^{\mathrm{a}}$ Conferencia General, 2003. París. Disponível em: http://portal.unesco.org Acessado em: 22 de Julho de 2016. 